\title{
Occasional hybridization between a native and invasive Senecio species in Australia is unlikely to contribute to invasive success
}

\author{
Eleanor E Dormontt ${ }^{\text {Corresp., } 1}{ }^{1}$, Peter J Prentis ${ }^{2}$, Michael G Gardner ${ }^{3}$ ， Andrew J Lowe ${ }^{\text {Corresp. } 1}$ \\ ${ }^{1}$ The Environment Institute, School of Biological Sciences, University of Adelaide, Adelaide, South Australia, Australia \\ 2 Institute for Future Environments, School of Earth, Environmental and Biological Sciences, Queensland University of Technology, Brisbane, Queensland, \\ Australia \\ 3 School of Biological Sciences, Flinders University of South Australia, Adelaide, South Australia, Australia \\ Corresponding Authors: Eleanor E Dormontt, Andrew J Lowe \\ Email address: eleanor.dormontt@adelaide.edu.au, andrew.lowe@adelaide.edu.au
}

Background. Hybridization between native and invasive species can facilitate introgression of native genes that increase invasive potential by providing exotic species with pre-adapted genes suitable for new environments. In this study we assessed the outcome of hybridization between native Senecio pinnatifolius var. pinnatifolius A.Rich. (dune ecotype) and invasive Senecio madagascariensis Poir. to investigate the potential for introgression of adaptive genes to have facilitated $S$. madagascariensis spread in Australia.

Methods. We used amplified fragment length polymorphisms (141 loci) and nuclear microsatellites (2 loci) to genotype a total of 118 adults and 223 seeds from S. pinnatifolius var.pinnatifolius and $S$. madagascariensis at one allopatric and two shared sites. We used model based clustering and assignment methods to establish whether hybrid seed set and mature hybrids occur in the field.

Results. We detected no adult hybrids in any population. Low incidence of hybrid seed set was found at

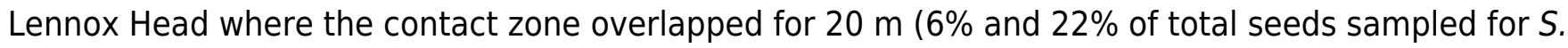
pinnatifolius var. pinnatifolius and $S$. madagascariensis respectively). One hybrid seed was detected at Ballina where a gap of approximately $150 \mathrm{~m}$ was present between species ( $2 \%$ of total seeds sampled for S. madagascariensis).

Conclusions. We found no evidence of adult hybrid plants at two shared sites. Hybrid seed set from both species was identified at low levels. Based on these findings we conclude that introgression of adaptive genes from $S$. pinnatifolius var. pinnatifolius is unlikely to have facilitated $S$. madagascariensis invasions in Australia. Revisitation of one site after two years could find no remaining $S$. pinnatifolius var.pinnatifolius, suggesting that contact zones between these species are dynamic and that $S$. pinnatifolius var.pinnatifolius may be at risk of displacement by S. madagascariensis in coastal areas. 


\section{Occasional hybridization between a native and an invasive}

\section{Senecio species in Australia is unlikely to contribute to}

\section{3 invasive success}

4 Eleanor E. Dormontt ${ }^{1}$, Peter J. Prentis ${ }^{2}$, Michael G. Gardner ${ }^{3}$, Andrew J. Lowe ${ }^{1}$

$5 \quad{ }^{1}$ The Environment Institute, School of Biological Sciences, University of Adelaide, Adelaide,

6 South Australia, Australia.

$7 \quad{ }^{2}$ Institute for Future Environments, School of Earth, Environmental and Biological Sciences,

8 Queensland University of Technology (QUT), Brisbane, Queensland, Australia

$9{ }^{3}$ School of Biological Sciences, Flinders University of South Australia, Adelaide, South

10 Australia, Australia.

12 Corresponding Author:

13 Andrew J. Lowe ${ }^{1}$

14 School of Biological Sciences, University of Adelaide Street Address, Adelaide, South Australia, 155005 , Australia

16 Email address: andrew.lowe@adelaide.edu.au 
19 Background. Hybridization between native and invasive species can facilitate introgression of

20 native genes that increase invasive potential by providing exotic species with pre-adapted genes

21 suitable for new environments. In this study we assessed the outcome of hybridization between

22 native Senecio pinnatifolius var. pinnatifolius A.Rich. (dune ecotype) and invasive Senecio

23 madagascariensis Poir. to investigate the potential for introgression of adaptive genes to have

24 facilitated S. madagascariensis spread in Australia.

25 Methods. We used amplified fragment length polymorphisms (141 loci) and nuclear

26 microsatellites (2 loci) to genotype a total of 118 adults and 223 seeds from $S$. pinnatifolius

27 var. pinnatifolius and S. madagascariensis at one allopatric and two shared sites. We used model

28 based clustering and assignment methods to establish whether hybrid seed set and mature

29 hybrids occur in the field.

30 Results. We detected no adult hybrids in any population. Low incidence of hybrid seed set was

31 found at Lennox Head where the contact zone overlapped for $20 \mathrm{~m}(6 \%$ and $22 \%$ of total seeds

32 sampled for S. pinnatifolius var. pinnatifolius and S. madagascariensis respectively). One hybrid

33 seed was detected at Ballina where a gap of approximately $150 \mathrm{~m}$ was present between species

34 (2\% of total seeds sampled for S. madagascariensis).

35 Conclusions. We found no evidence of adult hybrid plants at two shared sites. Hybrid seed set

36 from both species was identified at low levels. Based on these findings we conclude that

37 introgression of adaptive genes from $S$. pinnatifolius var. pinnatifolius is unlikely to have

38 facilitated S. madagascariensis invasions in Australia. Revisitation of one site after two years

39 could find no remaining $S$. pinnatifolius var. pinnatifolius, suggesting that contact zones between

40 these species are dynamic and that $S$. pinnatifolius var. pinnatifolius may be at risk of

41 displacement by $S$. madagascariensis in coastal areas. 


\section{Introduction}

44 The study of hybridization between related species has continued to fascinate biologists since the early 19th century (Stebbins 1959) with the potential role of hybridization in evolutionary diversification of particular interest (Abbott et al. 2013; Anderson \& Stebbins 1954; Arnold

47 2004; Seehausen 2004; Yakimowski \& Rieseberg 2014). Hybridization can have diverse 48 outcomes including the formation or extinction of species (Abbott et al. 2010; Rhymer \&

49 Simberloff 1996; Todesco et al. 2016), introgression of genes from one parental taxa to another

50 (e.g. Whitney et al. 2006; Whitney et al. 2010), and demographic swamping (e.g. Field et al.

51 2008; Prentis et al. 2007). Alternatively, successful hybridization between co-occurring species

52 may be rare enough to have little long-term impact on either parental taxa.

54 Hybridization between native and invasive species is of particular interest, indeed in their seminal review, Ellstrand \& Schierenbeck (2000) argue that hybridization (inter- and intraspecific) can act as a stimulus for the evolution of invasiveness. One mechanism by which this

57 can occur is through introgression of adaptive genes resulting from hybridization followed by repeated backcrossing with parental taxa. Introgression of native genes can increase invasive potential by providing exotic species with pre-adapted genes suitable for new environments (e.g. Whitney et al. 2010), conversely introgression of exotic genes can facilitate the transfer of weedy

61 traits to native species, jeopardizing genetic integrity (e.g. Fitzpatrick et al. 2010). Simulation

62 studies on neutral genes have revealed that the very nature of the invasive process is likely to

63 promote almost exclusively unidirectional introgression, from the native species into the invader 
64 (Currat et al. 2008) increasing the likelihood of locally adapted genes facilitating invasive

65 species spread. Aside from introgression, hybrid progeny can go on to become invasive species

66 in their own right, such as Senecio squalidus which evolved via homoploid hybrid speciation

67 from the parental species Senecio aethnensis and Senecio chrysanthemifolius (Abbott et al.

68 2010). In extreme cases, hybrid progeny can be so successful that they completely displace their

69 parental species in the field, such as the Californian wild radish, an invasive hybrid lineage

70 derived from introduced Raphanus sativus and Raphanus raphanistrum (Hegde et al. 2006).

72 In the current study, we focus on a native and invasive species pair, Senecio

73 pinnatifolius var. pinnatifolius A.Rich. (dune ecotype) and Senecio madagascariensis Poir.,

74 which co-occur along $2000 \mathrm{~km}$ of coast line in New South Wales, Australia. Senecio

75 madagascariensis is a successful invasive plant in Australia and typically a weed of agricultural

76 pastures, however it can also be found growing alongside the native $S$. pinnatifolius in natural

77 systems, raising the possibility that introgression of adaptive genes from the native has facilitated

78 its spread into these areas. In previous work on $S$. pinnatifolius var. serratus (tableland ecotype)

79 Prentis et al. (2007) found hybrid seed set but no adult hybrids in the field. Prentis et al. (2007)

80 also modelled loss of viable seeds to hybridization and predicted the eventual displacement of

81 S. pinnatifolius var. serratus by the invasive $S$. madagascariensis at their study sites.

83 Whether Prentis et al.'s (2007) conclusions are more broadly applicable to other S. pinnatifolius

84 ecotypes is not clear. Reports of potential hybrids between S. madagascariensis and

85 S. pinnatifolius var. pinnatifolius (dune ecotype) (Scott 1994; EM White, Queensland University 
86 of Technology, Australia, 'pers. comm.') have served as a stimulus for the current study which

87 sought to assess the incidence of hybridization between $S$. madagascariensis and S. pinnatifolius

88 var. pinnatifolius at two sites where the species co-occur. The species have overlapping flower

89 times (Radford 1997; Radford \& Cousens 2000) and share pollinators (White 2008) making

90 hybridization in the field possible. The two species do possess different ploidy however $(S$.

91 pinnatifolius is tetraploid, $S$. madagascariensis diploid) with the triploid hybrid offspring that

92 would most often result, typically having low fertility due to meiotic pairing problems between

93 homeologous chromosomes. Despite the low fertility typical of triploid hybrids, they have been

94 shown to act as a bridge between taxa facilitating introgression (Koutecký et al. 2011; Lowe \&

95 Abbott 2000) and it may be possible for S. madagascariensis to produce unreduced gametes

96 (Brownfield \& Köhler 2010; Koutecký et al. 2011; Ramsey \& Schemske 1998) that could fuse

97 with normal S. pinnatifolius gametes to produce tetraploid hybrid offspring.

As a successful invader, $S$. madagascariensis is spreading through south-eastern Australia into new habitats, possibly due in part to introgression of adaptive genes from $S$. pinnatifolius var.

101 pinnatifolius. As a first step to examining this possibility, we assessed the extent of hybrid seed

102 set and the incidence of adult hybrids at our field sites. We hypothesized that if introgression was 103 occurring between $S$. pinnatifolius var. pinnatifolius and S. madagascariensis, then evidence of

104 mature hybrids should exists at sites where the two species co-occur.

106 We use amplified fragment length polymorphisms (AFLPs) and microsatellites from mature

107 individuals of both species at two sites where the species co-occur and one site for each species 
108 that was at least $2 \mathrm{~km}$ away from any other known populations of the congener ('allopatric'). We

109 also sampled open pollinated progeny arrays in areas of co-occurrence. We asked whether hybrid

110 seed set occurs in the field and whether adult hybrids are present that could backcross with either

111 species to facilitate introgression.

113 Materials \& Methods

114 Study species

115 Senecio madagascariensis is a diploid plant, initially introduced to south-eastern Australia from

116 the KwaZulu-Natal province of South Africa in the early part of the $20^{\text {th }}$ century (Radford et al.

117 2000). Molecular analysis of contemporary and historical field collections has pointed to at least

118 two separate introductions (Dormontt et al. 2014). Senecio pinnatifolius (previously S. lautus) is

119 a tetraploid plant native to Australia. There have been multiple taxonomic treatments of the

120 species complex (Ali 1969; Radford 1997; Roda et al. 2013; Thompson 2005), with each

121 agreeing on distinction of 'dune', 'headland' and 'tableland ecotypes. Senecio pinnatifolius var.

122 pinnatifolius (dune ecotype) occurs on coastal sands along the east coast of Australia and is the

123 only S. pinnatifolius ecotype analysed in the current study, hereafter referred to only as Senecio

124 pinnatifolius. Initially included in the S. pinnatifolius complex, S. madagascariensis was

125 recognised as a separate species after Hilliard's (1977) treatment of Asteraceae in Natal (Sindel

126 et al. 1998). This separation has been supported by morphological comparisons (Thompson

127 2005) and cytological studies (Radford et al. 1995) finding $2 n=20$ for $S$. madagascariensis and $1282 n=40$ for S. pinnatifolius. 
130 Both species are considered annuals or short lived perennials (Radford \& Cousens 2000), look

131 superficially identical, growing to approximately $0.6 \mathrm{~m}$ and with bright green leaves and yellow

132 inflorescences that are heterogamous and radiate. The species can be reliably distinguished by

133 the number of involucral bracts present, 18-21 in S. madagascariensis, 11-14 in S. pinnatifolius.

134 Both species are outcrossing, self-incompatible (Ali 1966) and insect pollinated, predominantly

135 by the introduced European honey bee Apis mellifera and various species of Syrphidae (White

136 2008); seeds are wind dispersed. In comparisons of life history traits between the species,

137 S. madagascariensis was found to perform better than S. pinnatifolius with respect to seedling,

138 growth and fecundity measures but S pinnatifolius maintained a stronger soil seed bank (Radford

$139 \&$ Cousens 2000).

141 Sample collection and seed germination

142 One allopatric population of each species was sampled along with two sites where the two

143 species occurred together (Table 1). At each site, twenty individuals of each species were

144 sampled with fresh leaf material preserved in silica beads for DNA extraction. Additionally, at

145 shared sites, multiple mature seed heads were collected from sampled plants where available and

146 stored for later germination. Plants were sampled in a systematic fashion (across the contact zone

147 at shared sites) and the location of all plants recorded with GPS (with the exception of the

148 allopatric $S$. madagascariensis population where coordinates were not recorded). Plants that

149 were not sampled for DNA were identified in the field and GPS coordinates recorded. The GPS

150 recorded relative position to within $1 \mathrm{~m}$ accuracy. Two years after initial sampling, we revisited

151 one of the shared sites to survey the changes in abundance of S. pinnatifolius and

152 S. madagascariensis. 
154 In the laboratory, mature achenes were detached from their pappus and the seed coat nicked with

155 a scalpel. Seeds were grown on moist filter paper with gibberellic acid $\left(\mathrm{GA}_{3}\right)$ in a 12 hour

156 photoperiod at $25^{\circ} \mathrm{C}$ to stimulate germination. All germinated seedlings, up to a maximum of ten

157 per parent plant, were frozen at $-80^{\circ} \mathrm{C}$ prior to DNA extraction, except in one case where 20

158 seedlings were used (Table 1, see results for further explanation). The number of seeds per

159 parent plant that successfully germinated were classified as 'ten or more', or 'less than ten'.

160 Germination rates were compared between sites using a permutation approach in Resampling

161 Stats Add-In for Excel v4.0 (statistics.com). Seeds per parent plant that successfully germinated

162 ('ten or more', or 'less than ten') were sampled without replacement to simulate the same

163 number of parent plants per site as the empirical data. The proportion of 'less than ten' seedlings

164 per site were compared in 10,000 simulations to the empirical data to obtain estimated $P$ values.

166 Genetic analysis

167 DNA extractions were carried out using the Machery-Nagel Nucleospin Plant II Kit with the 168 PL2/PL3 buffer system. Two published microsatellite loci (Le Roux \& Wieczorek 2007)

169 originally developed for $S$. madagascariensis and found to be cross compatible with

170 S. pinnatifolius, were used to screen all adults and seedlings from both species (Table 2). PCR

171 reactions were prepared with $20 \mathrm{ng}$ of template DNA, 1x reaction buffer, $0.2 \mathrm{mM}$ of each

$172 \mathrm{dNTP}, 2.5 \mathrm{mM} \mathrm{MgCl} 2,0.4 \mu \mathrm{M}$ of each primer, and $0.02 \mathrm{U}$ Amplitaq Gold ${ }^{\circledR}$ (Applied

173 Biosystems) to give a final PCR reaction volume of $10 \mu \mathrm{L}$. Reactions involved an initial

174 denaturation step of $94{ }^{\circ} \mathrm{C}$ for 2 minutes, followed by 35 cycles at $94{ }^{\circ} \mathrm{C}$ for 1 minute, the loci 
175 specific annealing temperature for 1 minute (Table 2), $72{ }^{\circ} \mathrm{C}$ for 1 minute and 30 seconds, and a

176 final extension at $72{ }^{\circ} \mathrm{C}$ for 30 minutes. One published chloroplast microsatellite locus (Weising

177 and Gardner 1999) (Table 2) was found to produce bands mutually exclusive to S. pinnatifolius

178 and S. madagascariensis and so was included to allow identification of the maternal parent of

179 any hybrid adults detected in the field. Reactions were prepared with $\sim 20$ ng of template DNA,

$1801 \mathrm{x}$ reaction buffer, $0.2 \mathrm{mM}$ of each dNTP, $2.5 \mathrm{mM} \mathrm{MgCl}_{2}, 0.5 \mu \mathrm{M}$ of each primer, and $1 \mathrm{U}$

181 IMMOLASETM DNA polymerase (Bioline) to give a final PCR reaction volume of $10 \mu \mathrm{L}$.

182 Reactions involved an initial denaturation step of $94^{\circ} \mathrm{C}$ for 5 minutes, 30 cycles of $94^{\circ} \mathrm{C}$ for 20

183 seconds, $50^{\circ} \mathrm{C}$ for 20 seconds, $72^{\circ} \mathrm{C}$ for 20 seconds, and a final extension at $72^{\circ} \mathrm{C}$ for 30

184 minutes. Products were separated using the ABI 3730 DNA analyzer (Applied Biosystems) with

185 the GeneScan ${ }^{\mathrm{TM}}-500$ LIZ® size standard. Genemapper ${ }^{\circledR}$ Software v4.0 (Applied Biosystems)

186 was used to score fragments. Scoring was recorded in a binary matrix with presence or absence

187 of particular alleles indicated by a 1 or 0 . This method allowed for polyploidy and diploid data to

188 be directly compared and analysed together. DNA from thirty one individuals ( $9 \%$ of samples)

189 were amplified twice for microsatellite analysis to enable estimation of error rates, calculated

190 according to DeWoody et al. (2006).

192 Amplified fragment length polymorphisms (AFLPs) were assessed according to the method of

193 Vos et al. (1995) with modifications. Restriction digests were performed in $20 \mu$ reactions with

$194 \sim 200 \mathrm{ng}$ of DNA, $1 \mathrm{x}$ restriction digest buffer 2, $10 \mathrm{U}$ MseI (New England Biolabs), $10 \mathrm{U}$ EcoRI

195 (New England Biolabs), and $1 \times$ BSA. Reactions were incubated for 3 hours at $37^{\circ} \mathrm{C}$, followed

196 by 20 minutes at $65^{\circ} \mathrm{C}$ to denature the enzymes. Adapters were ligated to the digested fragments

197 in reactions containing $20 \mu \mathrm{l}$ of digested DNA, 1 x T4 ligase buffer, $2.5 \mu \mathrm{M}$ EcoRI adapter, 0.25 
$198 \mu \mathrm{M}$ MseI adapter and $3 \mathrm{U}$ of T4 DNA ligase (New England Biolabs). Reactions were incubated

199 overnight at $16^{\circ} \mathrm{C}$.

200

201 Pre-selective amplifications contained $2 \mu \mathrm{l}$ of digested and ligated DNA, 1 x Optimised

202 DyNAzyme ${ }^{\mathrm{TM}}$ EXT buffer (including $\left.1.5 \mathrm{mM} \mathrm{Mg}^{2+}\right), 0.2 \mathrm{mM}$ of each dNTP, $0.5 \mu \mathrm{M}$ MseI $(+\mathrm{C})$,

$203 \quad 0.5 \mu \mathrm{M}$ EcoRI $(+\mathrm{A})$ primers and $0.25 \mathrm{U}^{\mathrm{D}} \mathrm{DNAzyme} \mathrm{TM}^{\mathrm{TM}} \mathrm{EXT}$ DNA polymerase to give a final

204 PCR reaction volume of $25 \mu \mathrm{L}$. Reactions involved an initial denaturation step of $75^{\circ} \mathrm{C}$ for 2

205 minutes, then 20 cycles of $94{ }^{\circ} \mathrm{C}$ for 30 seconds, $56{ }^{\circ} \mathrm{C}$ for 30 seconds, $75^{\circ} \mathrm{C}$ for 2 minutes, and

206 a final extension at $60^{\circ} \mathrm{C}$ for 30 minutes. PCR products were run on agarose gel to check for 207 successful amplification.

209 Selective amplifications contained $1 \mu \mathrm{l}$ of 1 in 30 diluted pre-selective PCR product, $1 \mathrm{x}$

210 TaqGold buffer (Applied Biosystems), $2 \mathrm{mM} \mathrm{MgCl}_{2}, 0.2 \mathrm{mM}$ of each dNTP, $0.3 \mu \mathrm{M}$ MseI $+3 \mathrm{bp}$

211 primers, $0.3 \mu \mathrm{M}$ EcoRI +3 bp primers and $0.75 \mathrm{U}$ TaqGold (Applied Biosystems) in a final PCR

212 reaction volume of $15 \mu \mathrm{L}$. Reactions involved an initial denaturation step of $94{ }^{\circ} \mathrm{C}$ for 2 minutes,

213 then 10 cycles of $94{ }^{\circ} \mathrm{C}$ for 30 seconds, $65-56{ }^{\circ} \mathrm{C}$ for 30 seconds (reduce by $1^{\circ} \mathrm{C}$ per cycle), 72

$214{ }^{\circ} \mathrm{C}$ for 2 minutes, then 26 cycles of $94{ }^{\circ} \mathrm{C}$ for 30 seconds, $56{ }^{\circ} \mathrm{C}$ for 30 seconds, $72{ }^{\circ} \mathrm{C}$ for 2

215 minutes and a final extension at $60^{\circ} \mathrm{C}$ for 5 minutes. Twelve selective amplifications were trialled

216 using a range of $+3 \mathrm{bp}$ primer combinations on four individuals of each species. Products were

217 run on 5\% acrylamide gels using a Gelscan GS2000 (Corbet Research) and the three most

218 suitable combinations (based on appropriate number and strength of bands, polymorphisms and

219 ease of scoring) were chosen for selective amplification of all samples (Table 2). Products were 
220 separated using the ABI 3730 DNA analyzer (Applied Biosystems) with the GeneScan ${ }^{\mathrm{TM}}-500$

221 LIZ $®$ size standard. Forty one adult individuals ( $12 \%$ of total individuals) were re-extracted for

222 DNA and the AFLP process repeated to allow loci validation and error rate calculations.

223 Vegetative material from seedlings was too small to allow for repeated extractions, so only

224 adults were used. A negative control was included throughout the extraction/AFLP process to 225 enable exclusion of non-specific bands.

227 Genemapper® Software v4.0 (Applied Biosystems) was used to manually allocate bins to 228 appropriate loci, all duplicated samples were visualised and where consistent banding was 229 apparent between samples, this was assigned as a specific locus. Once manual binning was 230 complete, the full dataset was automatically scored using Genemapper ${ }^{\circledR}$ Software v4.0 (Applied 231 Biosystems) and raw peak height data obtained. The raw peak height data were then used with 232 AFLPScore v1.4 (Whitlock et al. 2008) to minimise error whilst maximising number of retained 233 loci. AFLPScore allows the user to select a range of loci selection thresholds (the average 234 intensity of bands at a specific locus, above which a locus is retained in the dataset) and 235 phenotype calling thresholds (the intensity of a given band, either in absolute terms, or as a 236 percentage of the average for that locus, above which band presence will be called). By

237 comparing combinations of different locus selection and phenotype calling thresholds, the user 238 can select thresholds which result in reduced error and maximised retained loci. After error 239 reduction via AFLPscore, a phenotype matrix was exported and loci with the highest error rates 240 systematically removed to create 11 separate datasets with error rates of $0 \%, 1 \%, 2 \%, 3 \%$ etc. up 241 to $10 \%$ and additionally one with a $17 \%$ error rate (the output from AFLPscore with no loci 242 removed). To assess the effects of each error rate on overall information content, the data from 
243 the allopatric populations of each species were analysed using the program STRUCTURE

244 (Pritchard et al. 2000) with RECESSIVEALLELES set to 1 to account for dominant data (Falush

245 et al. 2007). Number of predefined populations (K) was set from 1 to 5 . Each run consisted of a

246 burn-in period of 100,000 Markov Chain Monte Carlo (MCMC) repetitions, followed by

247 1,000,000 MCMC repetitions, the program was run five times to allow averaging of results in

248 CLUMPP (Jakobsson \& Rosenberg 2007). Plots were displayed in DISTRUCT (Rosenberg

249 2004). The final dataset was chosen based on how well it could detect the expected structure

250 (designation of $K=2$, highest probability of individuals belonging to the appropriate species

251 cluster) and how robust it was to the negative impacts of higher error (such as the signal from

252 plate effects) see Zhang \& Hare (2012) for an in-depth discussion and analysis of this approach.

254 Data analysis

255 To assess hybridisation, the AFLP and microsatellite data were combined into one data matrix, in

256 the case of the microsatellites, each allele was either designated as present or absent. Assignment

257 of an individual as either a pure parental species or a hybrid was based on a consensus between

258 two different analysis methods, with the most conservative (i.e. non-hybrid) designation accepted

259 if results were inconsistent between methods. The first method used the allocation procedure in

260 the program AFLPOP (Duchesne \& Bernatchez 2002). The allopatric populations of each

261 species were set as sources, and the remaining samples allocated to either one of the pure species

262 or hybrid origin by the program. Zero frequencies were corrected as $1 / n+1$, where $n$ is the

263 sample size. The allocation minimal log-likelihood difference (MLD) was initially set to 1

264 (meaning allocation only occurred when designation was 10 times more likely than any other

265 possible origin). Samples that could not be allocated in this way were re-run with MLD set to 0 
266 (allocating to highest likelihood source regardless of the magnitude of difference between

267 alternate likelihoods).

269 The second method used the program STRUCTURE (Pritchard et al. 2000) with extensions

270 implemented by Falush et al. (2007) to account for genotypic ambiguity that is inherent in

271 dominant markers; RECESSIVEALLELES was set to 1. STRUCTURE has been used

272 successfully to assess datasets comprised of individuals with different ploidy levels (De Hert et

273 al. 2012; Pinheiro et al. 2010; Zalapa et al. 2011). Number of predefined populations $(K)$ was set

274 to 2. Each run consisted of a burn-in period of 100,000 Markov Chain Monte Carlo (MCMC)

275 repetitions, followed by 1,000,000 MCMC repetitions, the program was run five times to allow

276 averaging of results in CLUMPP (Jakobsson \& Rosenberg 2007). Plots were displayed in

277 DISTRUCT (Rosenberg 2004). Clustering of adult and seedling genotypes of each species at

278 both allopatric and shared sites were visualised with a principal coordinate analysis ( $\mathrm{PCoA})$ in

279 GENALEX v6.4 (Peakall \& Smouse 2006; Peakall \& Smouse 2012). Hybrid zone mapping was

280 completed using ArcGIS v9.2 (ESRI 2009).

\section{RESULTS}

\section{Loci selection}

284 Both nuclear microsatellite loci were polymorphic in both species and retained for further

285 analysis (Table 2). The single chloroplast microsatellite locus was polymorphic in

286 S. pinnatifolius (2 alleles) and monomorphic in S. madagascariensis but alleles were not shared

287 between species. All adults and seedlings genotyped conformed to their expected species specific 
288 chloroplast haplotypes. The observed error rate per allele and per locus for the nuclear

289 microsatellites was zero. Of the 12 AFLP primer combinations trialled, three were chosen for

290 screening all samples (Table 2).

291

292 In AFLPScore v1.4 (Whitlock et al. 2008), mismatch error rates were used to optimise scoring

293 parameters using both absolute and relative phenotype calling thresholds on an initial dataset

294 containing 247 loci. The error rate of the exported data set was 0.17 with 233 retained loci (Data

295 S1), achieved by filtering data using an absolute phenotype-calling threshold of 250 relative

296 fluorescence units (RFU), prior to application of a 50 RFU locus-selection threshold. After

297 STRUCTURE analysis, the data set equating to an average error rate of $6 \%$ was chosen, as it

298 correctly identified $K=2$, indicated high assignment rates of individuals to their correct species,

299 did not display any significant plate effects at $K=3$ (the number of plates) and contained a

300 reasonable number of loci (142) (Fig. S1). An overall error rate of $6 \%$ is high compared to the 2-

$3015 \%$ reported for most AFLP studies (Bonin et al. 2004) but under the maximum threshold of

$30210 \%$ recommended by Bonin et al. (2007) (Fig. S2). Systematically evaluating the effects of

303 different error rates on result and selecting that which is most informative and least confounding

304 allows the information content of the dataset to be maximised without limiting the included loci

305 in order to conform to an arbitrary cut off point (Zhang \& Hare 2012).

306

307 Hybridisation

308 No adult hybrids were detected in the field. In total, 17 hybrids were observed from 223 seeds

309 ( $8 \%$ of seeds and $5 \%$ of all individuals genotyped including adults). Fourteen of these hybrid 
310 seeds were from a single S. madagascariensis mother and three from two S. pinnatifolius

311 mothers (Fig. 1). Hybrid seed set was observed at Lennox Head where $6 \%$ and $22 \%$ of the total

312 seeds sampled for each species at that site were hybrid for S. pinnatifolius and

313 S. madagascariensis respectively. For each adult with hybrid seed set, the distance to the nearest

314 congeneric was $<15 \mathrm{~m}$ (Fig. 1). There was uncertainty in the field about seeds collected from

315 what appeared to be a single plant but may have been two adjacent plants. Twenty seeds were

316 germinated from this sample with the hope that separation of individuals could be made in the

317 lab from the results of the genetic analysis. The microsatellite data confirmed that these seeds did

318 indeed come from the same individual, and so one adult has 20 genotyped offspring instead of

319 the usual 10. A single hybrid seed was detected at Ballina from a S. madagascariensis mother

320 (Fig 1), as designated by agreement between AFLPop and STRUCTURE, however this

321 individual does closely cluster with other pure S. madagascariensis seedlings in the PCoA

322 analysis (Fig. 2), which may indicate a false positive result. AFLPOP (Duchesne \& Bernatchez

3232002 ) allocated $90 \%$ of adults and $68 \%$ of seedlings with a minimal log-likelihood difference

324 (MLD) of 1 (indicating that the allocation was at least 10 times more likely than any other). The

325 remaining samples allocated with MLD set to 0 . One S. madagascariensis seedling was allocated

326 to S. pinnatifolius with MLD set to 0 . The chloroplast haplotype of this individual was consistent

327 with S. madagascariensis maternity and it clustered with the hybrid seedlings in the PCoA (Fig.

328 2), so has been designated as a hybrid. Hybrid origin was more conservatively allocated in the

329 program STRUCTURE (Pritchard et al. 2000) (Fig. 3) with 92\% consensus between the two

330 methods. Final designation used the most conservative (non-hybrid) allocation. 
333 Germination success varied somewhat between individuals with 11-38\% of parent plants per site

334 producing less than ten seedlings for DNA extraction. However, the simulation approach used to

335 examine germination rates found no significant differences between germination rates at each

336 site and those expected to arise randomly. The Lennox Head site was revisited in 2009, two years

337 after initial sampling and a morphological survey of plant species identity undertaken. All plants

338 observed were identified as $S$. madagascariensis.

340 Discussion

341 Hybridisation between native and exotic species can affect biological invasions in several ways,

342 including via introgression (Currat et al. 2008; Prentis et al. 2008; Whitney et al. 2006; Whitney

343 et al. 2010) and pollen swamping (Buggs \& Pannell 2006; Petit et al. 2004; Prentis et al. 2007).

344 Despite occasional hybrid seed set between native Senecio pinnatifolius var. pinnatifolius (dune

345 ecotype) and invasive Senecio madagascariensis, we found no evidence to support the role of

346 introgression in this system. We found very low levels of hybrid seed formation in both

347 S. pinnatifolius and S. madagascariensis mothers at one site (Lennox Head, NSW) where the two

348 species occur together with a minimum distance of approximately $15 \mathrm{~m}$. A single

349 S. madagascariensis mother and two S. pinnatifolius mothers produced all the hybrid seeds at

350 this site. At the other study site (Ballina, NSW) a single hybrid seed was detected in a

351 S. madagascariensis mother, with a distance of approximately $155 \mathrm{~m}$ to the closest

352 S. pinnatifolius plant. The observed imbalances in hybrid seed set amongst conspecifics may be

353 the result of proximity to congenerics (Fig. 1) or could indicate individual variation in ability to

354 set hybrid seed. 
356 No adult hybrids were identified at either site which could be explained simply by the low

357 overall hybrid seed set observed; perhaps hybrid adults were not present simply by chance in the 358 study year. Prentis et al. (2007) found no significant differences in viability between seeds

359 generated from intra- and inter-specific crosses suggesting that any fitness costs are incurred

360 after germination. However, Prentis et al. (2007) examined S. pinnatifolius var. serratus, not

361 S. pinnatifolius var. pinnatifolius (the focus of this study), so it is possible that hybrid seed

362 viability varies between $S$. pinnatifolius varieties. Reciprocal crossing experiments between

363 S. madagascariensis and the different $S$. pinnatifolius varieties would further explore this issue.

364 Alternatively, the lack of mature hybrids observed in the field could be the result of reduced

365 hybrid fitness acting as a post-zygotic mating barrier between $S$. pinnatifolius and

366 S. madagascariensis. Previous work has shown that synthetic hybrids between the two species

367 grown under glasshouse conditions had low viability and were sterile (Radford 1997).

368 Occasional adult hybrid occurrence may explain the findings of Scott (1994) and EM White,

369 Queensland University of Technology, Australia, 'pers. comm.' who report observation of 370 putative hybrid plants.

372 The present study did not identify the ploidy level of the hybrid seedlings identified from our

373 open pollinated progeny arrays which would be an interesting topic for further research.

374 Koutecký et al. (2011) found that hybrids formed from reduced gametes between diploid

375 Centaurea pseudophrygia and tetraploid Centaurea jacea were less common in the seed set of

376 maternal plants but more common in the adult hybrid plants found in the field, suggestive of

377 increased fitness of the tetraploid hybrids. These tetraploids were also able to backcross with 
378 C. jacea, facilitating introgression of C. pseudophrygia genes into C. jacea. In S. pinnatifolius $\mathrm{x}$

379 S. madagascariensis hybrids there may be similar fitness asymmetries associated with ploidy

380 level but as hybridisation rates were so low and no adult hybrids were detected in the present

381 study, the impact of any such differences is likely minimal.

382

383 Selection against hybrids in the field would constitute a post-zygotic mating barrier, yet the

384 prevailing view is that pre-zygotic mating barriers are stronger in flowering plants (Dell'Olivo et

385 al. 2011; Rieseberg \& Willis 2007; Widmer et al. 2009). However, global change (including

386 increased movement of exotic species) is predicted to increase opportunities for hybridization

387 through the erosion of pre-zygotic barriers (Vallejo-Marín \& Hiscock 2016). Evidence for pre-

388 zygotic isolation barriers between $S$. pinnatifolius and $S$. madagascariensis are sparse at present.

389 The two species can be found occurring in shared sites (Prentis et al. 2007; Radford 1997; White

390 2008), their flowering times overlap (Radford 1997; Radford \& Cousens 2000) and a similar suit

391 of pollinators visit both species (White 2008). However, it should be noted that reproductive

392 isolation can still be favoured even when flowering times overlap but not completely, as is the

393 case with $S$. pinnatifolius and S. madagascariensis (Radford 1997). And even when pollinators

394 are shared, they may prefer conspecific over heterospecific visitation (White 2008). The relative

395 contribution of these potentially reproductively-isolating barriers remains to be tested in this

396 system with more extensive field and laboratory studies, incorporating greater geographical and

397 temporal breadth. The use of AFLP and microsatellite markers to explore hybridization as

398 implemented in this study have also now been superseded by genomic techniques that utilize

399 next generation sequencing (NGS) methods to develop datasets with orders of magnitude more 
400 information (Goulet et al. 2017; Payseur \& Rieseberg 2016). Further work on the system should

401 exploit these resources to better characterise hybridisation outcomes.

402

403 We set out to explore whether hybridisation between S. pinnatifolius var. pinnatifolius (dune

404 ecotype) and S. madagascariensis was likely to have facilitated the spread of

405 S. madagascariensis by way of introgression of adaptive genes. Due to the very low level of

406 hybrid seed set and the absence of adult hybrids, we must conclude that introgression via fertile

407 hybrids in the field is probably rare, at least at the sites we studied. As only two field sites were

408 included it is difficult to generalise across the entire $\sim 2000 \mathrm{~km}$ range in which the two species

409 overlap, however we can tentatively support the findings of Prentis et al. (2007) who found

410 similar results in their study of hybridisation between $S$. pinnatifolius var. serratus (tableland

411 ecotype) and $S$. madagascariensis. It may be the case that all $S$. pinnatifolius ecotypes exhibit the

412 same patterns when in sympatry with S. madagascariensis.

414 In their modelling of these hybrid zones Prentis et al. (2007) also predicted a demographic

415 swamping of $S$. pinnatifolius by $S$. madagascariensis assuming that hybridisation is plant density

416 dependent. However, the very low levels of hybrid seed set observed in S. pinnatifolius in the

417 current study ( $6 \%$ of seeds) are not consistent with this prediction. The assumption of density

418 dependence could not be verified as overall levels of hybridisation were too low but we did find

419 the greatest proportion of hybrid seed set in an area of high congeneric plant density (Fig. 1). To

420 adequately assess the density dependent nature of hybridisation, artificial manipulation of plant

421 densities in open pollinated conditions would be required. At our subsequent revisitation of the 
422 Lennox Head site, two years after initial sampling, we were unable to find any S. pinnatifolius

423 individuals. Given the low levels of hybrid seed set, it is most likely that $S$. madagascariensis

424 achieved dominance via other competitive advantages such as longer flowering time, production

425 of more seeds and greater survival rates (Radford \& Cousens 2000). Both S. madagascariensis

426 and S. pinnatifolius are considered annuals or short lived perennials (Radford \& Cousens 2000),

427 stochastic recruitment failure in annual S. pinnatifolius combined with perennial behaviour in

428 some $S$. madagascariensis plants could also provide a plausible explanation for the lack of

429 S. pinnatifolius at the study site two years after collection.

430

431 Conclusion

432 Despite limited obvious pre-zygotic isolating barriers restricting hybridisation between the native

433 S. pinnatifolius var. pinnatifolius (dune ecotype) and invasive S. madagascariensis in coastal

434 areas of eastern Australia, we did not find any evidence of adult hybrid plants at two shared sites

435 surveyed in 2007 and analysed with a combination of AFLPs and microsatellites. Hybrid seeds

436 from both $S$. pinnatifolius and $S$. madagascariensis were identified at very low levels from open

437 pollinated progeny arrays in the field. Based on these investigations we conclude that

438 introgression of adaptive genes from $S$. pinnatifolius var. pinnatifolius (dune ecotype) is unlikely

439 to have played a significant role in the success of $S$. madagascariensis invasions in Australia.

441 Acknowledgements

442 We thank Dr. Ana Pavasovic for her support with field work and Dr. Evelyn White for her

443 communications regarding potential hybrids in the field. We also thank Dr. Gregory Owens and 
444 three anonymous reviewers whose constructive reviews greatly improved the quality of the

445 manuscript.

446

447

\section{References}

448

449

450

451

452

453

454

455

456

457

458

459

460

461

462

463

464

465

Abbott R, Albach D, Ansell S, Arntzen JW, Baird SJE, Bierne N, Boughman J, Brelsford A, Buerkle CA, Buggs R, Butlin RK, Dieckmann U, Eroukhmanoff F, Grill A, Cahan SH, Hermansen JS, Hewitt G, Hudson AG, Jiggins C, Jones J, Keller B, Marczewski T, Mallet J, Martinez-Rodriguez P, Most M, Mullen S, Nichols R, Nolte AW, Parisod C, Pfennig K, Rice AM, Ritchie MG, Seifert B, Smadja CM, Stelkens R, Szymura JM, Vainola R, Wolf JBW, and Zinner D. 2013. Hybridization and speciation. Journal of Evolutionary Biology 26:229-246.

Abbott RJ, Hegarty MJ, Hiscock SJ, and Brennan AC. 2010. Homoploid hybrid speciation in action. Taxon 59:1375-1386.

Ali SI. 1966. Senecio lautus complex in Australia. III. The genetic system. Australian Journal of Botany 14:317-327.

Ali SI. 1969. Senecio lautus complex in Australia. V. Taxonomic interpretations. Australian Journal of Botany 17:161-176.

Anderson E, and Stebbins GL, Jr. 1954. Hybridization as an evolutionary stimulus. Evolution 8:378-388.

Arnold ML. 2004. Transfer and origin of adaptations through natural hybridization: Were Anderson and Stebbins right? Plant Cell 16:562-570. 
466 Bonin A, Bellemain E, Eidesen PB, Pompanon F, Brochmann C, and Taberlet P. 2004. How to

467

468

469

470

471

472

473

474

475

476

477

478

479

480

481

482

483

484

485

486

487

488 track and assess genotyping errors in population genetics studies. Molecular Ecology $13: 3261-3273$.

Bonin A, Ehrich D, and Manel S. 2007. Statistical analysis of amplified fragment length polymorphism data: a toolbox for molecular ecologists and evolutionists. Molecular Ecology 16:3737-3758.

Brownfield L, and Köhler C. 2010. Unreduced gamete formation in plants: mechanisms and prospects. Journal of Experimental Botany.

Buggs RJA, and Pannell JR. 2006. Rapid displacement of a monoecious plant lineage is due to pollen swamping by a dioecious relative. Current Biology 16:996-1000.

Currat M, Ruedi M, Petit RJ, and Excoffier L. 2008. The hidden side of invasions: massive introgression by local genes. Evolution 62:1908-1920.

De Hert K, Jacquemyn H, Van Glabeke S, Roldan-Ruiz I, Vandepitte K, Leus L, and Honnay O. 2012. Reproductive isolation and hybridization in sympatric populations of three Dactylorhiza species (Orchidaceae) with different ploidy levels. Annals of Botany 109:709-720.

Dell'Olivo A, Hoballah ME, Gubitz T, and Kuhlemeier C. 2011. Isolation barriers between Petunia axillaris and Petunia integrifolia (Solanaceae). Evolution 65:1979-1991.

DeWoody J, Nason JD, and Hipkins VD. 2006. Mitigating scoring errors in microsatellite data from wild populations. Molecular Ecology Notes 6:951-957.

Dormontt EE, Gardner MG, Breed MF, Rodger JG, Prentis PJ, and Lowe AJ. 2014. Genetic bottlenecks in time and space: reconstructing invasions from contemporary and historical collections. Plos One 9:e106874. 
489 Duchesne P, and Bernatchez L. 2002. AFLPOP: a computer program for simulated and real 490 population allocation, based on AFLP data. Molecular Ecology Notes 2:380-383.

491 Ellstrand NC, and Schierenbeck KA. 2000. Hybridization as a stimulus for the evolution of 492 invasiveness in plants? Proceedings of the National Academy of Sciences of the United 493 States of America 97:7043-7050.

494 Falush D, Stephens M, and Pritchard JK. 2007. Inference of population structure using 495 multilocus genotype data: dominant markers and null alleles. Molecular Ecology Notes 7:574-578.

497 Field DL, Ayre DJ, Whelan RJ, and Young AG. 2008. Relative frequency of sympatric species 498 influences rates of interspecific hybridization, seed production and seedling performance in the uncommon Eucalyptus aggregata. Journal of Ecology 96:1198-1210.

Fitzpatrick BM, Johnson JR, Kump DK, Smith JJ, Voss SR, and Shaffer HB. 2010. Rapid spread 501 502 of invasive genes into a threatened native species. Proceedings of the National Academy of Sciences 107:3606-3610.

Goulet BE, Roda F, and Hopkins R. 2017. Hybridization in plants: old ideas, new techniques. Plant Physiology 173:65-78.

Hegde SG, Nason JD, Clegg JM, and Ellstrand NC. 2006. The evolution of California's wild radish has resulted in the extinction of its progenitors. Evolution 60:1187-1197.

507 Hilliard OM. 1977. Compositae in Natal. Pietermaritzburg: University of Natal Press.

508 Jakobsson M, and Rosenberg NA. 2007. CLUMPP: a cluster matching and permutation program 509 for dealing with label switching and multimodality in analysis of population structure.

$510 \quad$ Bioinformatics 23:1801-1806. 
511 Koutecký P, Bad'urová T, Štech M, Košnar JAN, and Karásek J. 2011. Hybridization between

512 diploid Centaurea pseudophrygia and tetraploid C. jacea (Asteraceae): the role of mixed

513 pollination, unreduced gametes, and mentor effects. Biological Journal of the Linnean

$514 \quad$ Society 104:93-106.

515 Le Roux JJ, and Wieczorek AM. 2007. Isolation and characterization of polymorphic

516 microsatellite markers from fireweed, Senecio madagascariensis Poir. (Asteraceae).

$517 \quad$ Molecular Ecology Notes 7:327-329.

518 Lowe AJ, and Abbott RJ. 2000. Routes of origin of two recently evolved hybrid taxa: Senecio

519 vulgaris var. hibernicus and York radiate groundsel (Asteraceae). American Journal of

$520 \quad$ Botany 87:1159-1167.

521 Payseur BA, and Rieseberg LH. 2016. A genomic perspective on hybridization and speciation.

522 Molecular Ecology.

523 Peakall R, and Smouse PE. 2006. GENALEX 6: genetic analysis in Excel. Population genetic 524 software for teaching and research. Molecular Ecology Notes 6:288-295.

525 Peakall R, and Smouse PE. 2012. GenAlEx 6.5: genetic analysis in Excel. Population genetic 526 software for teaching and research—an update. Bioinformatics 28:2537-2539.

527 Petit RJ, Bodenes C, Ducousso A, Roussel G, and Kremer A. 2004. Hybridization as a 528 mechanism of invasion in oaks. New Phytologist 161:151-164.

529 Pinheiro F, de Barros F, Palma-Silva C, Meyer D, Fay MF, Suzuki RM, Lexer C, and Cozzolino 530 S. 2010. Hybridization and introgression across different ploidy levels in the Neotropical 531 orchids Epidendrum fulgens and E. puniceoluteum (Orchidaceae). Molecular Ecology 19:3981-3994. 
533 Prentis PJ, White EM, Radford IJ, Lowe AJ, and Clarke AR. 2007. Can hybridization cause local

534 extinction: a case for demographic swamping of the Australian native Senecio

535 pinnatifolius by the invasive Senecio madagascariensis? New Phytologist 176:902-912.

536 Prentis PJ, Wilson JRU, Dormontt EE, Richardson DM, and Lowe AJ. 2008. Adaptive evolution 537 in invasive species. Trends in Plant Science 13:288-294.

538 Pritchard JK, Stephens M, and Donnelly P. 2000. Inference of population structure using 539 multilocus genotype data. Genetics 155:945-959.

540 Radford IJ. 1997. Impact assessment for the biological control of Senecio madagascariensis Poir $541 \quad$ (fireweed). PhD thesis. University of Sydney.

542 Radford IJ, and Cousens RD. 2000. Invasiveness and comparative life-history traits of exotic and indigenous Senecio species in Australia. Oecologia 125:531-542.

544 Radford IJ, Liu Q, and Michael PW. 1995. Chromosome counts for the Australian weed known as Senecio madagascariensis (Asteraceae). Australian Systematic Botany 8:1029-1033.

546 Radford IJ, Muller P, Fiffer S, and Michael PW. 2000. Genetic relationships between Australian fireweed and South African and Madagascan populations of Senecio madagascariensis

548 Poir. and closely related Senecio species. Australian Systematic Botany 13:409-423.

549 Ramsey J, and Schemske DW. 1998. Pathways, mechanisms, and rates of polyploid formation in $550 \quad$ flowering plants. Annual review of ecology and systematics 29:467-501.

551 Rhymer JM, and Simberloff D. 1996. Extinction by hybridization and introgression. Annual 552 review of ecology and systematics 27:83-109.

553 Rieseberg LH, and Willis JH. 2007. Plant speciation. Science 317:910-914. 
554 Roda F, Ambrose L, Walter GM, Liu HL, Schaul A, Lowe A, Pelser PB, Prentis P, Rieseberg

555 LH, and Ortiz-Barrientos D. 2013. Genomic evidence for the parallel evolution of coastal 556 forms in the Senecio lautus complex. Molecular Ecology 22:2941-2952.

557 Rosenberg NA. 2004. DISTRUCT: a program for the graphical display of population structure. $558 \quad$ Molecular Ecology Notes 4:137-138.

559 Scott L. 1994. Fireweed (Senecio madagascariensis Poir.) is not part of the Senecio lautus 560 complex: phylogenetic evidence using ITS1 DNA sequences, Honours Thesis. University $561 \quad$ of Queensland.

562 Seehausen O. 2004. Hybridization and adaptive radiation. Trends in Ecology \& Evolution $563 \quad 19: 198-207$.

564 Sindel BM, Radford IJ, Holtkamp RH, and Michael PW. 1998. The biology of Australian weeds: 33. Senecio madagascariensis Poir. Plant Protection Quarterly 13:2-15.

Stebbins GL. 1959. The role of hybridization in evolution. Proceedings of the American Philosophical Society 103:231-251.

568 Thompson IR. 2005. Taxonomic studies of Australian Senecio (Asteraceae): 5. The $S$.

569 pinnatifolius/S. lautus complex. Muelleria 21:23-76.

570 Todesco M, Pascual MA, Owens GL, Ostevik KL, Moyers BT, Hübner S, Heredia SM, Hahn

571 MA, Caseys C, and Bock DG. 2016. Hybridization and extinction. Evolutionary $572 \quad$ Applications.

573 Vallejo-Marín M, and Hiscock SJ. 2016. Hybridization and hybrid speciation under global 574 change. New Phytologist. 
575 Vos P, Hogers R, Bleeker M, Reijans M, Van de Lee T, Hornes M, Friters A, Pot J, Paleman J,

576 and Kuiper M. 1995. AFLP: a new technique for DNA fingerprinting. Nucleic acids

$577 \quad$ research 23:4407-4414.

578 White EM. 2008. Indirect interactions between alien and native Senecio species as mediated by insects PhD. Queensland University of Technology.

580 Whitlock R, Hipperson H, Mannarelli M, Butlin RK, and Burke T. 2008. An objective, rapid and 581 reproducible method for scoring AFLP peak-height data that minimizes genotyping error. Molecular Ecology Resources 8:725-735.

583 Whitney KD, Randell RA, and Rieseberg LH. 2006. Adaptive introgression of herbivore 584 resistance traits in the weedy sunflower Helianthus annuus. American Naturalist

Whitney KD, Randell RA, and Rieseberg LH. 2010. Adaptive introgression of abiotic tolerance traits in the sunflower Helianthus annuus. New Phytologist 187:230-239.

Widmer A, Lexer C, and Cozzolino S. 2009. Evolution of reproductive isolation in plants. Heredity 102:31-38.

590 Yakimowski SB, and Rieseberg LH. 2014. The role of homoploid hybridization in evolution: a century of studies synthesizing genetics and ecology. American Journal of Botany 101:1247-1258.

Zalapa JE, Price DL, Kaeppler SM, Tobias CM, Okada M, and Casler MD. 2011. Hierarchical classification of switchgrass genotypes using SSR and chloroplast sequences: ecotypes, ploidies, gene pools, and cultivars. Theoretical and Applied Genetics 122:805-817. 
596 Zhang H, and Hare MP. 2012. Identifying and reducing AFLP genotyping error: an example of 597 tradeoffs when comparing population structure in broadcast spawning versus brooding $598 \quad$ oysters. Heredity 108:616-625.

599 


\section{Table $\mathbf{1}$ (on next page)}

Information on sites and samples included in the study.

Number of adults sampled $\left(n_{\mathrm{a}}\right)$, number of adults with genotyped seedlings $\left(n_{s}\right)$, number of seedlings analysed $(s)$ and range of seedlings genotyped per mother plant. 


\begin{tabular}{|c|c|c|c|c|c|c|}
\hline Species & Population & Latitude & Longitude & $n_{a}$ & $n_{s}$ & $s$ (range) \\
\hline \multirow[t]{3}{*}{ S. pinnatifolius } & Southport & S $27^{\circ} 56^{\prime} 15^{\prime \prime}$ & E $153^{\circ} 25^{\prime} 35^{\prime \prime}$ & 20 & 0 & - \\
\hline & Lennox Head & S $28^{\circ} 47^{\prime} 9^{\prime \prime}$ & E $153^{\circ} 35^{\prime} 38^{\prime \prime}$ & 20 & 7 & $52(2-10)$ \\
\hline & Ballina & S $28^{\circ} 52^{\prime} 25^{\prime \prime}$ & E $153^{\circ} 35^{\prime} 21^{\prime \prime}$ & 20 & 7 & $61(4-10)$ \\
\hline \multirow[t]{4}{*}{ S. madagascariensis } & Oxenford & S $27^{\circ} 53^{\prime} 23^{\prime \prime}$ & E $153^{\circ} 18^{\prime} 43^{\prime \prime}$ & 18 & 0 & - \\
\hline & Lennox Head & $\mathrm{S} 28^{\circ} 47^{\prime} 9^{\prime \prime}$ & E $153^{\circ} 35^{\prime} 38^{\prime \prime}$ & 20 & 6 & $59(10-19)$ \\
\hline & Ballina & $\mathrm{S} 28^{\circ} 52^{\prime} 25^{\prime \prime}$ & E $153^{\circ} 35^{\prime} 21^{\prime \prime}$ & 19 & 6 & $51(4-10)$ \\
\hline & & & Total & 117 & 26 & $223(2-19)$ \\
\hline
\end{tabular}




\section{Table 2 (on next page)}

Details of final round PCR primers used in study.

Markers used were amplified fragment length polymorphisms (AFLP), nuclear microsatellites (nSSR), and one chloroplast microsatellite (cPSSR). Primer information includes primer type (ECORI or Mse origin for AFLPs, locus name and primer direction for microsatellites); primer sequence including fluorescent dye (PET, FAM, NED or VIC); annealing temperature $\left(T_{a}\right)$; and number of loci (for AFLPs) or alleles (for microsatellites) scored for each pair ( $n$ ). 


\begin{tabular}{|c|c|c|c|c|c|c|}
\hline Marker & & Primer \#1 & & Primer \#2 & $\begin{array}{c}T_{a} \\
\left({ }^{\circ} \mathbf{C}\right)\end{array}$ & $n$ \\
\hline \multirow[t]{3}{*}{ AFLP } & EcoRI & $\begin{array}{l}\text { TACTGCGTACCAATTC } \\
\text { AGC(PET) }\end{array}$ & Mse & $\begin{array}{l}\text { GACGATGAGTCCTGA } \\
\text { GTAACAA }\end{array}$ & $65-56$ & 48 \\
\hline & EcoRI & $\begin{array}{l}\text { TACTGCGTACCAATTC } \\
\text { AGC(FAM) }\end{array}$ & Mse & $\begin{array}{l}\text { GACGATGAGTCCTGA } \\
\text { GTAACAG }\end{array}$ & $65-56$ & 57 \\
\hline & EcoRI & $\begin{array}{l}\text { TACTGCGTACCAATTC } \\
\text { AGC(NED) }\end{array}$ & Mse & $\begin{array}{l}\text { GACGATGAGTCCTGA } \\
\text { GTAACCG }\end{array}$ & $65-56$ & 37 \\
\hline \multirow[t]{2}{*}{ nSSR } & $\begin{array}{r}\text { Se- } \\
116 \mathrm{~F}\end{array}$ & $\begin{array}{l}\text { CCTTCTGGTTGATTTG } \\
\text { GCTAAGC(FAM) }\end{array}$ & $\begin{array}{r}\text { Se- } \\
116 R\end{array}$ & $\begin{array}{l}\text { AGAACTGCACATTTG } \\
\text { AAGCCTG }\end{array}$ & 48 & 15 \\
\hline & $\begin{array}{r}\text { Se- } \\
138 \mathrm{~F}\end{array}$ & $\begin{array}{l}\text { ACTTCGTGGGCCATTC } \\
\text { CAG(VIC) }\end{array}$ & $\begin{array}{r}\text { Se- } \\
138 \mathrm{R}\end{array}$ & $\begin{array}{l}\text { CTTCCTGCATAACATC } \\
\text { CACCAC }\end{array}$ & 58 & 24 \\
\hline cpSSR & $\begin{array}{r}\text { Ccmp3 } \\
\text { F }\end{array}$ & $\begin{array}{l}\text { CAGACCAAAAGCTGA } \\
\text { CATAG(PET) }\end{array}$ & $\begin{array}{r}\mathrm{Ccmp} \\
3 \mathrm{R}\end{array}$ & $\begin{array}{l}\text { GTTTCATTCGGCTCCT } \\
\text { TTAT }\end{array}$ & 50 & 3 \\
\hline
\end{tabular}




\section{Figure 1 (on next page)}

Location of samples at shared field sites.

Panel A shows location of sites in Australia; panel B shows location of sites in New South Wales; panel C shows the Ballina site; panel D shows the Lennox Head site. Senecio pinnatifolius is depicted with white symbols, Senecio madagascariensis with black symbols. The position of un-sampled plants is shown by crosses, small circles are genotyped adult plants, and larger circles are genotyped plants with genotyped seed. The proportion of seeds with pure or hybrid origin is shown in the large circles, grey indicating hybrid. Where hybrids occur, call out boxes enlarge this detail. Number of seeds sampled per adult $(n)$ is indicated. 


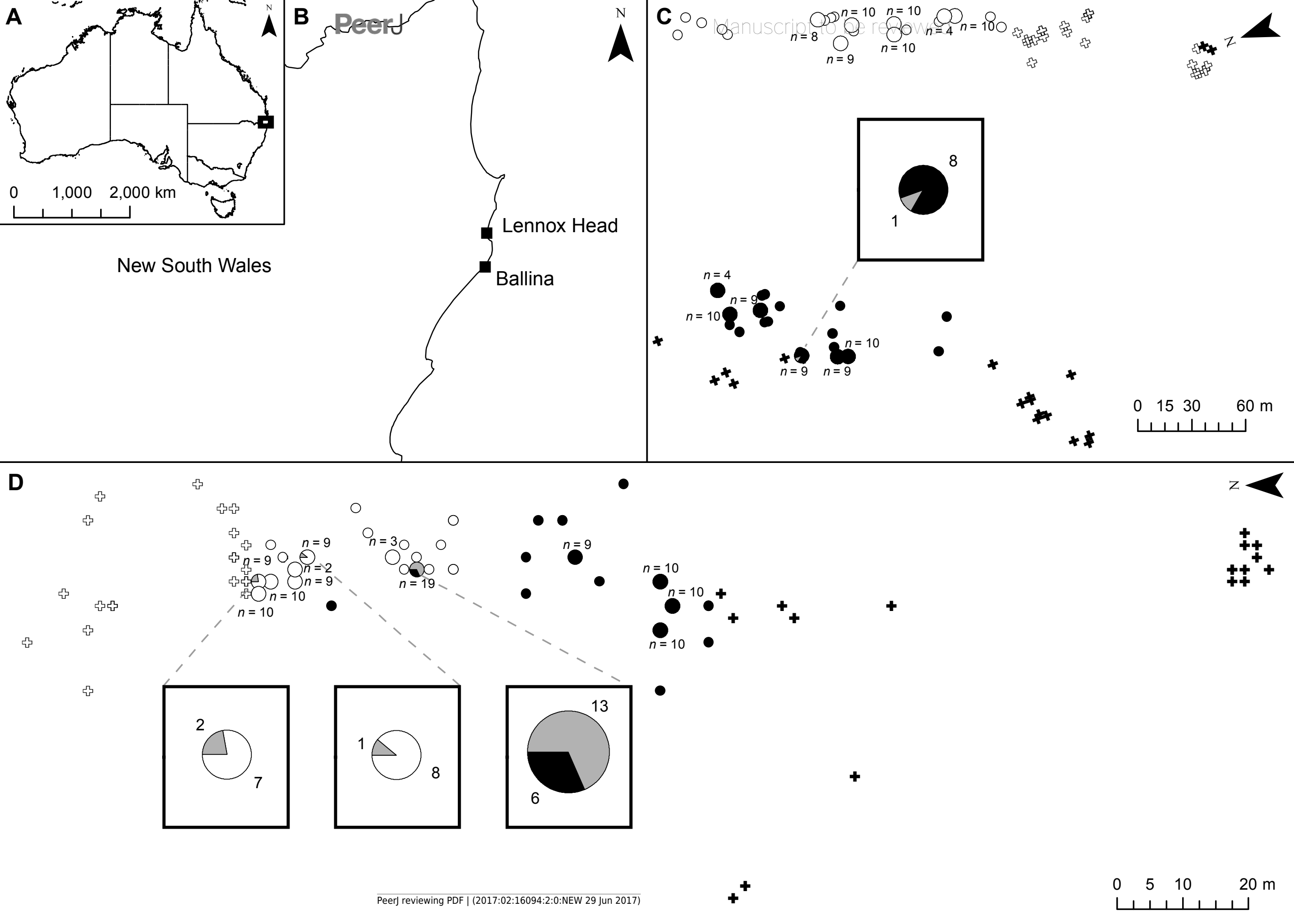


Figure 2 (on next page)

Principal coordinates analysis.

Clustering of adults (panel A) and seeds (panel B) of Senecio pinnatifolius (circles) and Senecio madagascariensis (triangles) at allopatric (grey) and the two shared sites: Lennox Head (white) and Ballina (black). Hybrid designation is based on the combined results from STRUCTURE and AFLPop. Hybrid seeds were found at Lennox Head with S. pinnatifolius mothers $(+)$ and $S$. madagascariensis mothers $(\mathrm{X})$. One hybrid with an S.madagascariensis mother was found at Ballina ( $\mathcal{K})$. 


\section{Figure 3}

Data output from the program STRUCTURE, runs averaged with CLUMPP and displayed with DISTRUCT.

Panel A shows data for Senecio pinnatifolius and panel B for Senecio madagascariensis. Locations, and whether the samples were adults or seeds, are shown under the bar plots. For both species, the allopatric population is shown first, followed by the shared sites. Individuals designated as hybrid in the final dataset are indicated with an asterisk.

A

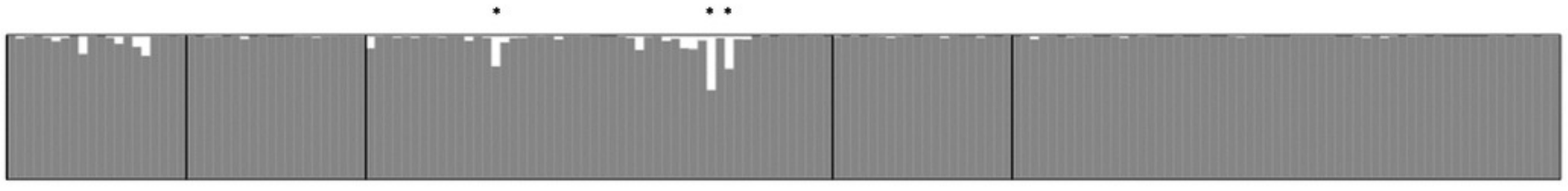

B
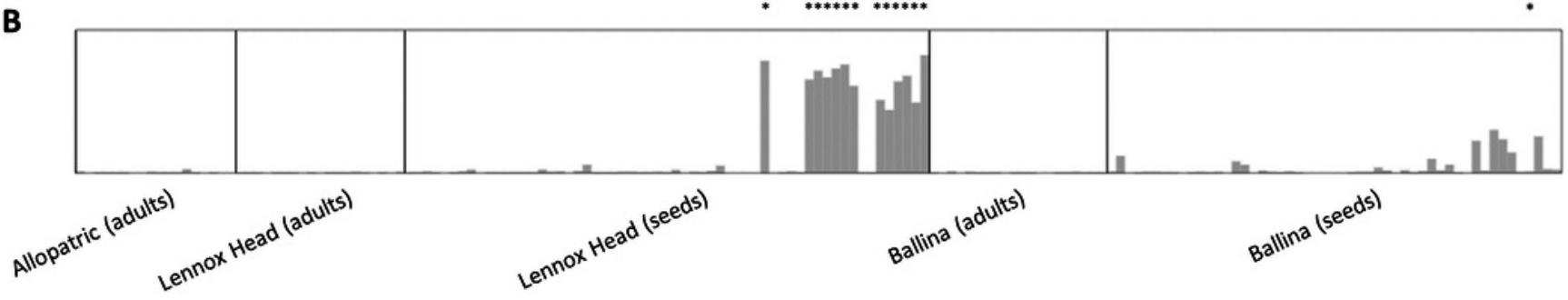